\title{
New species of the Neotropical genus Campatonema Jones (Geometridae, Ennominae) with the first description of the female
}

\author{
J. Bolling Sullivan \\ 200 Craven St., Beaufort, North Carolina 28516 USA \\ urn:lsid:zoobank.org:author:1D269A70-1054-4C69-A283-B8C24F6AE14C \\ Corresponding author: J. Bolling Sullivan (sullivan14@earthlink.net)
}

Academic editor: Christian Schmidt | Received 22 January 2010 | Accepted 11February 2010 | Published 18 March 2010

urn:lsid:zoobank.org:pub:C2CCE334-1AD5-4B4E-8270-B2CAA14537BE

Citation: Sullivan JB (2010) New species of the Neotropical genus Campatonema Jones (Geometridae, Ennominae) with the first description of the female. In: Schmidt BC, Lafontaine JD (Eds) Contributions to the systematics of New World macro-moths II. ZooKeys 39: 263-272. doi: 10.3897/zookeys.39.433

\begin{abstract}
Two new species of Campatonema Jones are described, C. tapantia sp. n. from Costa Rica and C. yanayacua sp. n. from Ecuador. A third species, Campatonema lineata (Schaus), is transferred to Campatonema from "Sabulodes." The female of Campatonema is described for the first time, and the tribal placement of Campatonema is discussed.
\end{abstract}

\section{Keywords}

Taxonomy, Campatonema, Sabulodes, Ourapterygini, Costa Rica, Ecuador

\section{Introduction}

In her review of the Neotropical ennomine geometrids, Pitkin (2002) placed Campatonema in the tribe Ourapterygini?, with some reservations. The only species of Campatonema described at the time, C. marginata Jones, was known only from several males from Brazil. The genus was not placed in Ourapterygini sensu stricto because the furca of $C$. marginata was not clearly homologous to the furca that characterizes the Ourapterygini. The tapered, pointed furca and the distinctive yellowish-cream color and pattern of the wings were used to characterize the genus Campatonema. 
Recent collecting in Costa Rica and Ecuador has turned up specimens of three additional species of Campatonema, including the first females. Pitkin et.al. (1996) did not report the genus from Costa Rica.

\section{Materials and methods}

\section{Repository abbreviations}

BMNH Natural History Museum, London, UK

INBI Instituto Nacional de Biodiversidad, Santo Domingo de Heredia, Costa Rica

JBS J. Bolling Sullivan, Beaufort, North Carolina, USA

USNM National Museum of Natural History, Washington, District of Columbia, USA

Photographic methods used herein are described in Sullivan and Adams (2009). Procedures for dissecting and preparing genitalia follow that of Lafontaine (2004). DNA sequencing of the barcode fragment of the COI gene was carried out at the Canadian Center for DNA barcoding in Guelph, Ontario. Barcode sequences were compared by nearest neighbor analyses as implemented on the Barcode of Life Data systems website (Ratnasingham and Hebert 2007).

\section{Systematics}

\section{Campatonema Jones}

Campatonema Jones, 1921: 334. Type species, Campatonema marginata Jones (1921) (by monotypy).

Pitkin (2002) characterized Campatonema by its peculiar furca (tapered, pointed shape), by the shape of the band on the dorsal forewing, and by the pointed, creamcolored forewing. In the three new species the furca is typical, of the Ourapterygini and located near the middle of the juxta and able to deflect to either side. The shape of the dark band on the dorsal forewing is variable among species, and the creamcolored forewing can be overlaid with reddish-brown scaling. The pointed forewing is characteristic. The unusual setal arrangement on the antenna with two rows of setae per segment on the ventral surface is a useful character for separating species of Campatonema from similar looking species in other genera. The genitalia are rather simple and have few characters useful for diagnosing the genus, so members of the genus are most easily recognized by a combination of wing shape, maculation, and antennal structure. 


\section{Campatonema tapantia Sullivan sp. $\mathrm{n}$.}

urn:Isid:zoobank.org:act:CCE3C74F-B405-41D9-AC2E-D78201A5BFC6

Figs 1, 2, 6a, b, 9

Type material. Holotype $\widehat{\text { }}$ : Costa Rica, Tapanti National Park, Orosi, Cartago Province, 1300-1400 m, 9 April 1984, D. H. Janzen and W. Hallwachs (INB0004129291)

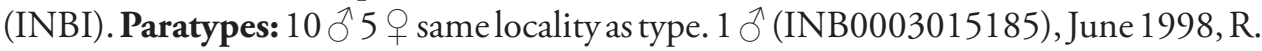

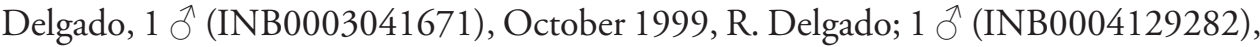
17 November 1982, Janzen and Hallwachs; 1 đ’(INB0004129288), 23 January 1985, Janzen and Hallwachs; 1 ठे(INB0004129289), 9 April 1984, Janzen and Hallwachs; $1 \widehat{\jmath}($ INB0004129290), 9 April 1984, Janzen and Hallwachs; 1 ઈ12-17 February 2006, J. Bolling Sullivan, 3 đ 7-9 July 2008, J. Bolling Sullivan; 1 \&(INBIOCRI002025033), October 1994, R. Delgado; 1 (INBIOCRI002553384), 17 November 1982, Janzen and Hallwachs; 1 \% 7-9 July 2008, J. Bolling Sullivan; 2 q 5-9 August 2007, 1480m, La Paz Waterfall Garden, Vera Blanca, Montana Azul, Alajuela Province, J. Bolling Sullivan. (INBI, BMNH, USNM, JBS).

Etymology. The name refers to Tapanti National Park, Costa Rica, the location where C. tapantia has been found most frequently.

Diagnosis. The species is readily recognized by its maculation. The dark chocolate line running from the middle of the lower forewing margin to the outer margin in combination with the chocolate marginal bands are diagnostic.

Description. Male. Head - Palps very small, less than eye width, third segment half length of first and second segments, which are equal in size. Palp with chocolate-brown scaling on outer and dorsal surface, cream on inner and ventral surfaces; frons squarish; ground cream with chocolate-brown dusting becoming dense dorsally; scape cream; area between antennae dirty cream; collar chocolate with erect brown scales. Antenna bifasciculate, segments Y-shaped, orange on ventral surface, dorsal scaling brown, lighter toward antennal tip. Setal rows arranged in two groups per segment, one at midpoint of segment, other at distal end on lateral expansions of segment. Thorax and abdomen - Thorax cream dorsally; abdominal segments cream with heavy brown dusting laterally especially on first segment; ventral surface cream. Legs dusted with fine brown scales dorsally, otherwise cream. Metathoracic tibia slightly swollen. Two pairs of tibial spurs on hind legs, one pair on middle legs. Wings - forewing length $15 \mathrm{~mm}$; ground color cream; costa and margin of forewing chocolate brown; chocolate submarginal line begins subapically on costa and runs parallel to wing margin to slightly below midpoint, (between M1 and M2) then angles to midpoint of lower margin of wing. Postmedial line (PM) indistinct. Discal spot chocolate, small but prominent. Hindwing ground cream, crossed by a series of brown lines parallel to margin. Discal dot distinct, medial line prominent. Wing margin dark brown, chocolate scaling forming a subapical spot. Fringe brown. Dorsal surface cream with brown dusting overlay particularly where PM line originates subapically, line incomplete, not extending to anal edge of wing. Margin with distinct line of chocolate scales. Discal spots distinct on both wings. Apex with a well defined white area. Male genitalia - Uncus rod shaped. Valva elongate, sweeping 


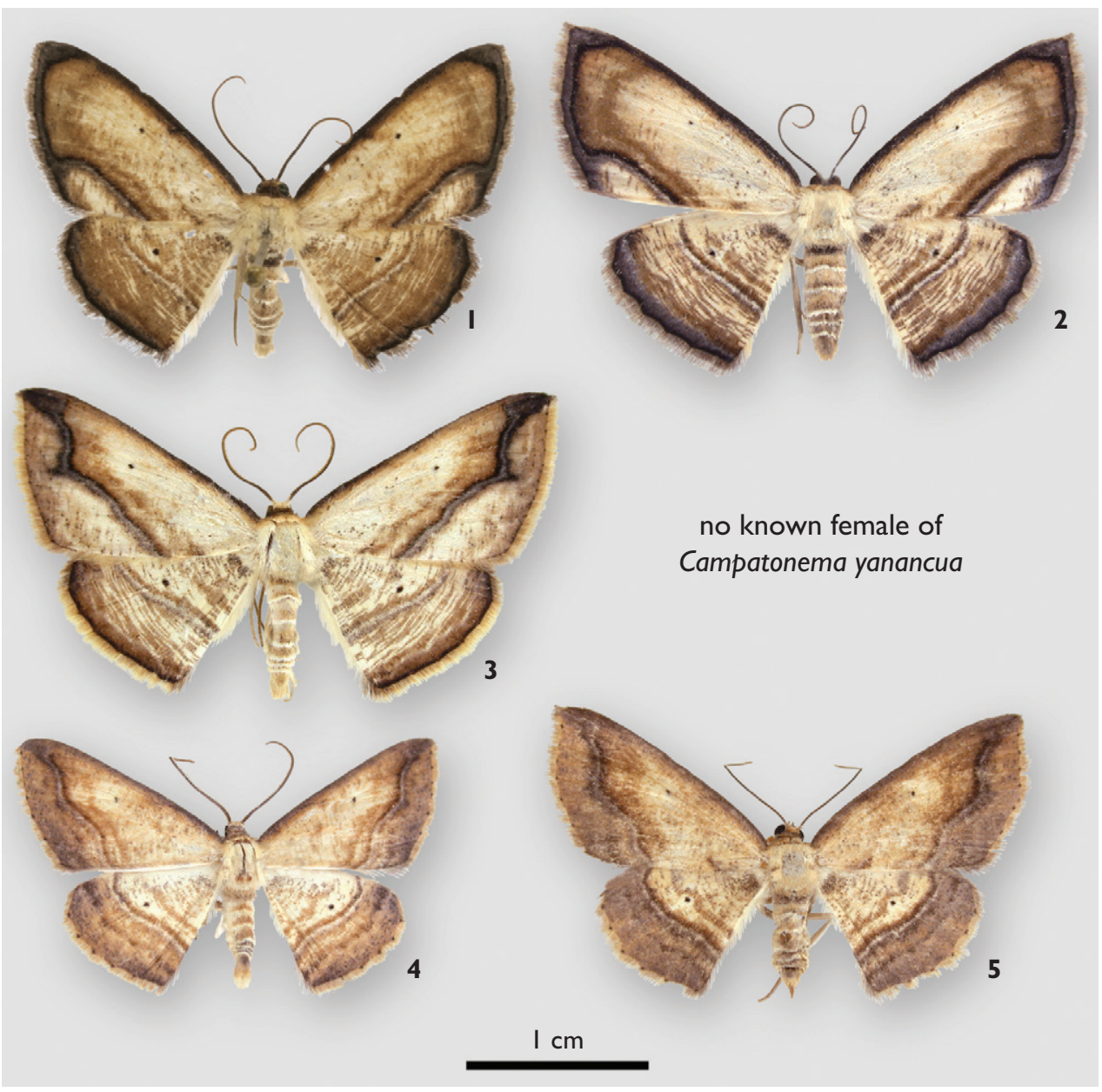

Figures I-5. Adults of Campatonema. I Campatonema tapantia Sullivan, male holotype, Tapanti National Park, Orosi, Cartago Province, Costa Rica, 9 April 2, 19842 Campatonema tapantia Sullivan, female paratype, La Paz Waterfall Garden, Vera Blanca, Montana Azul, Alajuela Province, Costa Rica, 5-9 August 2007 3 Campatonema yanayacua Sullivan, male paratype, Yanayacu Biological Station, $5 \mathrm{~km}$ West of Cosanga, Napo Province, Ecuador, 20 January 20094 Campatonema lineata (Schaus), male, Monteverde Biological Station, Monteverde, Puntarenas, Costa Rica, 23-27 August 20035 Campatonema lineata (Schaus), female, Monteverde Biological Station, Monteverde, Puntarenas, Costa Rica, 23-27 August 2003.

upward slightly toward uncus. Costal edge sclerotized with hairlike bristles below costal edge more numerous toward valve apex, which is acute and slants slightly upward. Arms of gnathos indistinct, medial junction forming oval pad and covered with spines. Anellar arms swollen and appear as an inward extension of costa. Tegumen arms extended diagonally to fuse posteriorly below uncus. Vincular arms straight. Furca diverted to left to gnathos, apex pointed; bristle area occupies terminal 15\%. Right juxtal arm swollen at base. Saccus with squared base. Aedeagus straight, lightly sclerotized, with basal keel, expands medially, apex acutely pointed. Vesica expanded slightly with patch 
of cornuti basally and hair-like bristles distally. No distinct features on pelt. Female. Antenna filiform, otherwise similar to male but slightly larger (FW length $16 \mathrm{~mm}$ ) and with chocolate dusting more extensive. Underside of forewing with distinct apical spot. Female genitalia - Anal papillae elongated, tip rounded, extended on ventral side. Posterior apophyses $2 \times$ length of anterior apophyses, thin, expanded and paddle shaped at terminus. Anterior apophyses kinked at posterior end, paddle shaped at terminus, but less broadly than posterior apophyses. Seventh tergite forms lightly sclerotized shield over ostium. Ostium sclerotized, oval with posterior margin deeply concave on left side. Ductus very long; bursa saclike; signa a narrow slit. Pelt without distinct features.

Distribution and biology. C. tapantia has been collected in the provinces of Alajuela, Cartago, and Heredia, Costa Rica. It has been found along a rather narrow elevational range, from 1100-1600 m. Adults are on the wing throughout the year.

\section{Campatonema yanayacua Sullivan sp. $\mathbf{n}$.}

urn:lsid:zoobank.org:act:764D6838-29F2-4CA1-9BF6-14CE93B65A98

Figs 3, 4, 7a, b

Type material. Holotype ${ }^{\top}$ : Ecuador, Yanayacu Biological Station, $4 \mathrm{~km}$ west of Cosanga, Napo Province, 2160 m, 20 January 2009, J. S. Miller, D. Wagner and R. Tapia, (USNM) Paratypes: 2 males. Same data as holotype except 18 January 2009. (BMNH, JBS).

Etymology. Campatonema yanayacua is named for the type locality, Yanayacu Biological Station, Napo, Ecuador.

Diagnosis. This species is readily recognized by the shape of the forewing PM line, which has an outward deflection at M3 that allows it to be distinguished from the other species of Campatonema.

Description. Male. Head - Palp slightly longer than width of eye; mid-segment longer than first and about $4 \times$ length of third; first two segments light brown outwardly with scattered chocolate scales. Cream scaling just below third segment with a few brown and chocolate scales dorsally. All segments with cream scaling inwardly. Frons squared with cream scales near palps and a mixture of brown and chocolate scales over the upper $80 \%$. Area between antennae with scales cream, erect; collar cream with brown scales adjacent to thorax; thorax cream with scattered brown scales. Antenna fasciculate, segments flared distad with bristle rows at middle and at distal end; antenna brown dorsally with two scale rows per segment. Thorax and abdomen - Abdomen cream with brown bands of varous shades; Abdominal segments cream basally becoming pale-brown posteriorly with white ring on posterior margin. Underside cream with scattered brown scales. Forelegs with brown scaling dorsally, cream ventrally. Hind tibia slightly swollen. Two pairs of tibial spurs on hind leg, one pair on middle legs. Wings - Forewing length 15-17 mm. PM line a double brown line, outer element fading on lower half of wing, middle part of PM line with blue gray; PM line expanded outwardly to form dark-brown wedge-shaped patch at forewing apex; medial area with a diffuse 


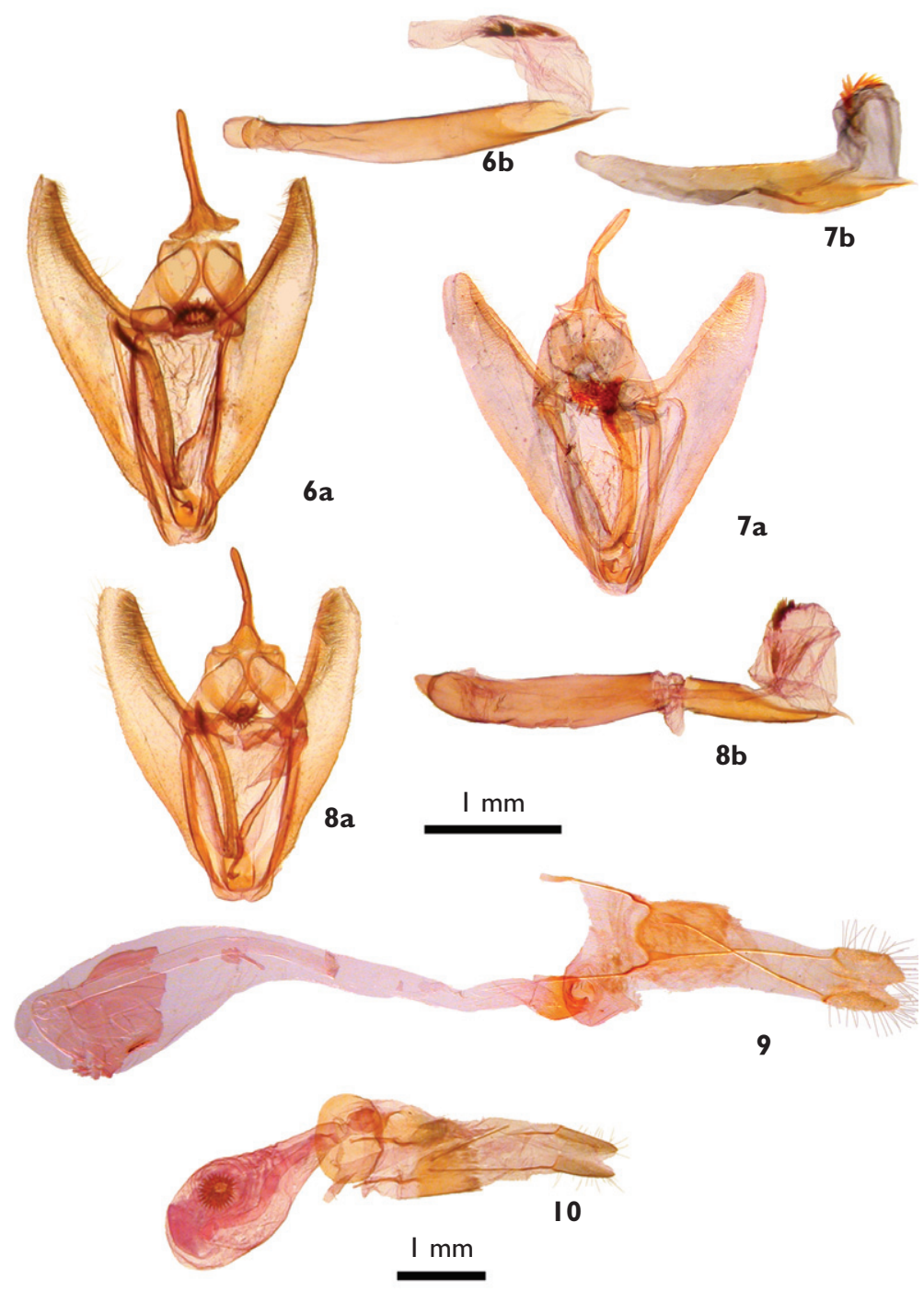

Figures 6-10. Genitalia of Campatonema. a valves $\mathbf{b}$ aedeagus 6a,b Campatonema tapantia Sullivan, male, Cartago Province, Costa Rica (JBS 1497) 7a,b Campatonema yanayacua Sullivan, male, Napo Province, Ecuador (JBS 2803) 8a,b Campatonema lineata (Schaus), male, Puntarenas Province, Costa Rica (JBS 1498) 9 Campatonema tapantia Sullivan, female, Alajuela Province, Costa Rica (JBS 1494) 10 Campatonema lineata (Schaus), female, Puntarenas Province, Costa Rica (JBS 1499).

brownish-gray band along inner margin of PM line. Costa brown basally becoming tan throughout mid-section and fusing with PM line at apex. Wing margin with row of chocolate scales forming terminal line, slightly wider at veins. Discal dot distinct. Hindwing with a series of tan and brown lines parallel to margin and crossing cream ground; brownish-gray PM line with blue-gray filling prominent. Margin a broad brown band. Ventral surface cream with chocolate PM line on costal half of forewing. Wing apex 
almost white. Discal dots distinct. Brown scaling over cream ground color particularly strong in costal area. Male genitalia - Uncus rod shaped, valves elongate, tapering to a rounded apex. Costa heavily sclerotized, with a slight bulge $1 / 3$ from apex. Costal half of valva with fine setae, without processes or well-defined ridges. Gnathos arms poorly defined, medial junction a well-defined pad covered with bristles or spines. Furca deflecting to right and extending to slightly above medial pad on gnathos. Outer third of furca with bristles. Furca slightly S-shaped, tapering little from base to rounded tip. Saccus slightly rounded. Aedeagus diameter increasing posteriorly before ending abruptly in a narrow spine; lightly sclerotized, particularly anteriorly. Everted vesica expanded slightly with a patch of 8 cornuti. Pelt without distinct features. Female. unknown.

Distribution. Known only from the type locality, Yanayacu Biological Station, Ecuador.

Remarks. Similar specimens have been collected at Estacion Cientifica San Francisco, Zamora-Chinchipe, Ecuador by Gunnar Brehm. Pictures of the adults and dissections of the genitalia were examined, but differ enough from the Yanayacu specimens that they are not included in the type series.

\section{Campatonema lineata (Schaus) comb. $\mathbf{n}$.}

Figs 4, 5, 8a, b, 10

Sabulodes? lineata Schaus, 1911: 590.

Type material. Syntypes: USNM. Type locality: Juan Vinas, Costa Rica.

Diagnosis. Campatonema lineata is readily separated from the other species of Campatonema by its wing pattern. In particular, no other species of Campatonema has broad, reddish-brown bands along the margins of both sets of wings.

Redescription. Male. Head - Palp short, less than length of round eye, slightly porrect, third segment $1 / 2$ length of first two segments, which are equal in length. Palp mostly cream on inner surface and brown on external surface. Frons rectangular, brown. Area between antennae and scape cream. Antenna fasciculate with bristles originating in middle and distal end of each segment; antenna brown dorsally, two rows of scales per segment, distal row darker. Scales of collar erect, dirty cream in color. Thorax and abdomen - Dorsal thoracic scales cream with two tan spots on distal end. Abdomen cream with tan scales on posterior half of each segment, segments 6-7 with dorsal scales brown, tipped with cream, segment 8 tan with darker brown central spot. Ventral abdomen cream. Legs finely scaled with grey brown dorsally, cream ventrally, two pairs of tibial spurs on hind leg, one pair on middle leg. Wings - Forewing length $14 \mathrm{~mm}$. Forewing slightly pointed, ground color cream heavily dusted with tan and chocolate brown; PM line originating subapically on costa and undulating to point at outer 1/4 of lower margin; PM line double on costal half, formed by two rows of chocolate scales with only inner one prominent and continuing to lower margin of wing. Traces of other tan lines parallel to wing margin both proximal and distal to PM 
line. Discal dot dark, distinct. Hindwing much as forewing, with a series of lines parallel to margin. PM line distad of discal dot darkest and most prominent. Margins of both wings tan with small chocolate patches at ends of veins. Ventral surface of wings with cream ground color and dusting of brown scales, becoming denser distally before forming a distinct marginal band. Apex of forewing lighter and forming a light band on forewing parallel to margin. Female. Slightly larger than male (forewing length 15 $\mathrm{mm}$ ), maculation much like male but colors more intense. Antenna filiform. Male genitalia - Uncus rod shaped; gnathos arms indistinct, medial pad oval and covered with spines. Valves slightly shorter than in other species, more rounded apically. Area of bristles on valves adjacent to sclerotized costa and broadest apically. Annelar arms appear bifurcate, without sclerotized medial area. Arms of tegumen meeting medially below uncus, fused. Vincular arms straight. Furca deflected to left, extending to gnathos and with bristled area toward apex. Saccus squared. Juxta bending slightly to median at base. Aedeagus straight, pointed at apex, vesica expanded with patch of cornuti which areith cornuti slightly larger on basal side of patch. Pelt without distinct features. $\mathrm{Fe}$ male genitalia - Anal papillae elongated with apex rounded. Posterior apophyses twice as long as anterior ones, thin, straight, paddlelike at apex. Anterior apophyses with knob-like junction about $1 / 3$ distance from posterior end, causing a slight redirection. Terminal ends paddlelike. Seventh tergite forming an oval shield with sclerotized ostial area below. Sclerotization on ostium forming a half collar dorsally. Ductus very short, forming a narrow neck to bursa, which expands slightly forming tear-drop shape. Signum on dorsal side a spiked sphere with hollow center. Pelt without distinct features.

Distribution and biology. Specimens have been collected in the provinces of Alajuela, Cartago, Guanacaste, and Puntarenas, Costa Rica, at elevations of 700-1500 m. Adults are on the wing throughout the year.

\section{Discussion}

Based on a single male of Campatonema marginata, Pitkin (2002) characterized the genus Campatonema by its tapered, pointed forewing shape and yellowish-cream wing color with tan border and a tan band crossing the dorsal surface of both wings. The peculiar furca-like process of C. marginata prevented Pitkin from including Camptonema in the Ourapterygini. The discovery of three additional species of Camptonema, all with a normal furca, supports placement of Camptonema in Ourapterygini. Camptonema is characterized by the tapered, pointed wing shape. The yellowish-cream wing color is distinctive in most members but can be overlayed with lines parallel to the wing margin which can extend inwardly past the discal spot. Antennal pectination, strongly fasciculate to bifasciculate with rows of bristles at the midpoint and at the terminus of each segment, will distinguish Camptonema from similar appearing species of Isochromodes Warren and Eusarca Hübner. The female genitalia offer no diagnostic characters, in part because the signum varies from a simple ridge to a stellate hollow 
sphere in the two known species. The female from southern Ecuador that was excluded from $N$. yanayacua also has a signum which is a stellate hollow sphere.

Camptonema species occur at moderate elevations (1000-2000 m) in Costa Rica and Ecuador, with an outlying species in Brazil. Almost nothing is known regarding the life history. C. tapantia usually came to mercury vapor and blacklights between 8-9 $\mathrm{pm}$. None of the species appears to be common and the number of sites where they have been found in Costa Rica and Ecuador are few. Additional species undoubtedly await discovery.

Bar-code data from two individuals of each of the two new species added to the genus Campatonema form a monophyletic cluster with no close generic relatives among the many hundreds of ennomine species that have been barcoded. Both Eusarca and Isochromodes include species externally similar to Campatonema and barcoding indicates they may be the most closely related genera but both are likely to be polyphyletic and in need of revision.

\section{Acknowledgements}

I would like to thank Jocelyn Gill, Don Lafontaine, and Chris Schmidt at CNC; Jocelyn for preparing the illustrations, Don and Chris for suggestions regarding the manuscript. Paul Hebert of the University of Guelph, Guelph, Canada allowed the use of unpublished barcode data. Isidro Chacon provided both data and images for Campatonema specimens in the collections at INBI. Gunnar Brehm and Frank Huenefeld (Institut fur Spezielle Zoologied und Evolutionsbiologie mit Phyletischem Museum, Jena, Germany) provided pictures of adults and genitalia for Campatonema specimens collected at the Estacion Cientifica San Francisco, Zamora-Chinchipe, Ecuador. James S. Miller graciously provided specimens collected at Yanayacu Biological Station. This work was supported in part by National Science Foundation grants DEB-0717173 and DEB-0849361 to Lee Dyer.

\section{References}

Jones ED (1921) Descriptions of new moths from south-east Brazil. Proceedings of the Zoological Society of London B 1921: 327-356.

Lafontaine JD (2004) Noctuoidea, Noctuidae (part), Noctuinae (part - Agrotini). In: Hodges RW (Ed) The Moths of America North of Mexico fasc. 27.1. The Wedge Entomological Research Foundation, Washington, 385 pp.

Pitkin L (2002) Neotropical ennomine moths: a review of the genera (Lepidoptera: Geometridae). Zoological Journal of the Linnean Society 135: 121-401.

Pitkin L, Mora RA, Scoble MJ (1996) A checklist to the Ennominae (Geometridae) of Costa Rica: taxonomy for a national biodiversity inventory. Gayana Zoolologia 60: 121-155. 
Ratnasingham S, Herbert PD (2007) Bold: The barcode of life data system. Molecular Ecology Notes 7: 355-364.

Sullivan JB, Adams J (2009) A new species of Morrisonia (Noctuidae) from Southeastern North America. Journal Lepidopterists' Society 63: 21-26.

Schaus, W (1911) New species of Heterocera from Costa Rica. XI. Annals and Magazine of Natural History 8: 577-602. 